\title{
EFFECT OF TEMPERATURE ON BLUEBIRD AND SWALLOW NESTING DATES
}

RONALD A. BITTNER, Box 97, Abernethy, Saskatchewan. SOA OAO

The author monitors a bluebird trail about every 5 days during the nesting season in the Abernethy area. This schedule usually allows the determination of the exact date when egg laying starts. Daily minimum and maximum temperatures are also recorded; they are measured in a ventilated enclosure and are comparable to official weather office readings.

The results presented here are based on 37 Mountain Bluebird and 60 Tree Swallow nestings over the 3-year period from 1988 to 1990 . Nesting dates are compared to monthly average temperatures and then to daily readings.

Since bluebirds arrive around the beginning of April and start nesting by early May it would be expected that their nesting dates would be influenced by April, and to some extent, May temperatures. Swallows which arrive around the beginning of May and start nesting by the end of May should be influenced only by May readings.

Table 1 gives the monthly mear temperatures (average of highs and lows for 3 months together with first egg-dates for bluebirds and swallows. It shows tha bluebirds nested at about the same dates in 1988 and 1989. These years hao similar temperatures for April and agair in May. In 1990 they nested about a week later. April was $2^{\circ}$ cooler and May 3 cooler than the previous 2 years. Swal. lows were also about a week later in 1990 due to the cooler May. They were slightly earlier in 1988 than 1989 which is no explained by the May temperatures; and we cannot use the hot June of 1988 as an explanation because most swallows are nesting by the beginning of June.

Using average monthly temperatures may be too coarse to explain all variations in nesting dates. Figure 1 shows bluebird nesting activity for 2 years

Table 1. THREE-YEAR COMPARISION OF MONTHLY TEMPERATURES AND FIRSTEGG DATES FOR MOUNTAIN BLUEBIRDS AND TREE SWALLOWS.

\begin{tabular}{|lccc|}
\hline Year & 1988 & 1989 & 1990 \\
\hline Nestboxes monitored & 36 & 48 & 66 \\
Bluebird nestings (1st brood) & 9 & 14 & 14 \\
Swallow nestings & 15 & 22 & 23 \\
Monthly mean T April & 4.8 & 4.6 & 2.7 \\
Monthly mean T May & 13.5 & 13.3 & 10.4 \\
Monthly mean T June & 21.5 & 16.4 & 16.3 \\
Bluebirds earliest 1st egg & 1 May & 3 May & 9 May \\
Bluebirds median 1st egg & 13 May & 12 May & 20 May \\
Swallows earliest 1st egg & 23 May & 27 June & 31 May \\
Swallows median 1st egg & 27 May & 1 June & 8 June \\
\hline
\end{tabular}


together with daily temperatures. The upper part of each graph shows the number of nestboxes with nests in various stages of completion. The lower part shows the daily high and low temperatures. In 1989 temperatures were fairly uniform and mostly above normal. This led to a steady progression in nesting activity. In 1990 late April was cold, preceded and followed by warm spells. Nesting activity was rapid during the warm weather and ceased during the cold weather.

Late April was also wet with 1 inch of precipitation during the cold period. The effect of precipitation on nesting dates is beyond the scope of this paper.
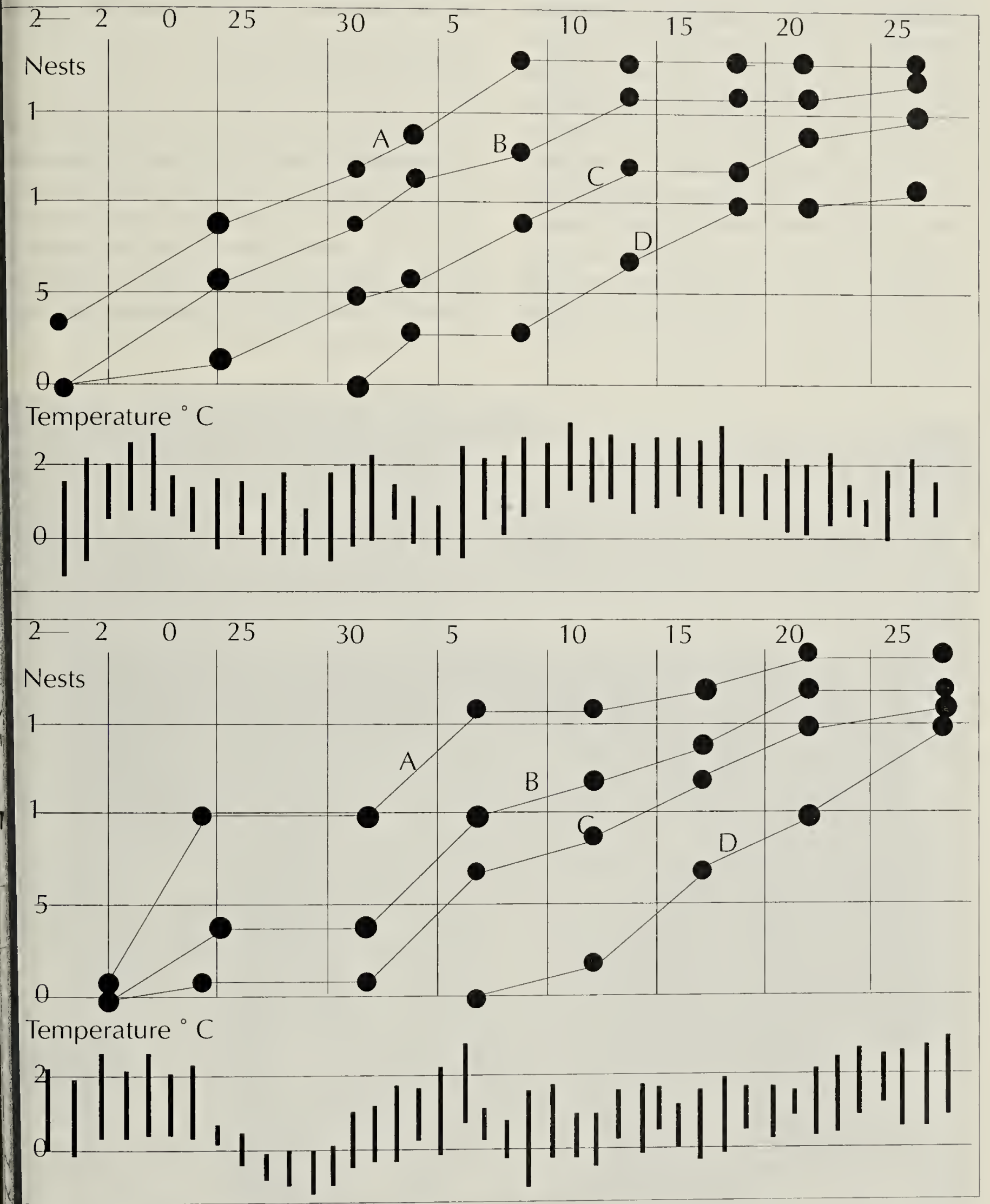

gure 1. Mountain Bluebird nesting dates with daily minimum and maximum emperature. $A$ - nests started $B$ - nests half finished $C$ - nests finished $D$ - with eggs 